\title{
Growth of a Copper-Gold Alloy Phase by Bulk Copper Electrodeposition on Gold Investigated by In Situ STM
}

\section{Andersen, Jens Enevold Thaulov; Møller, Per}

Published in:

Journal of The Electrochemical Society

Publication date:

1995

Document Version

Publisher's PDF, also known as Version of record

Link back to DTU Orbit

Citation (APA):

Andersen, J. E. T., \& Møller, P. (1995). Growth of a Copper-Gold Alloy Phase by Bulk Copper Electrodeposition on Gold Investigated by In Situ STM. Journal of The Electrochemical Society, 142(7), 2225-2232.

http://dx.doi.org/10.1149/1.2044279

\section{General rights}

Copyright and moral rights for the publications made accessible in the public portal are retained by the authors and/or other copyright owners and it is a condition of accessing publications that users recognise and abide by the legal requirements associated with these rights.

- Users may download and print one copy of any publication from the public portal for the purpose of private study or research.

- You may not further distribute the material or use it for any profit-making activity or commercial gain

- You may freely distribute the URL identifying the publication in the public portal 


\title{
Growth of a Copper-Gold Alloy Phase by Bulk Copper Electrodeposition on Gold Investigated by In Situ STM
}

\author{
Jens E. T. Andersen and Per Moller \\ Centre of Advanced Electroplating, The Technical University of Denmark, DK-2800 Lyngby, Denmark
}

\section{ABSTRACT}

Simultaneous in situ scanning tunneling microscopy measurements and recordings of voltammograms were used to study in real time the initial cycles of potentiostatic copper electrodeposition and subsequent dissolution on a clean gold polycrystalline electrode. The cycles were carried out by sweeping the potential in the double-layer charging region from 500 to $-100 \mathrm{mV}$ and back to $500 \mathrm{mV}$ at a sweep rate of $1 \mathrm{mV} / \mathrm{s}$ in an acidified copper sulfate electrolyte $\left(0.01 M \mathrm{H}_{2} \mathrm{SO}_{4}, 0.01 \mathrm{M}\right.$ $\mathrm{CuSO}_{4}$, and Millipore water). After completion of the first cycle the gold surface had recrystallized and nuclei of an alloy phase were formed. After completion of subsequent cycles the distribution of crystallite dimensions and the shape of the crystallites changed and the growth was compared with features of concomitant voltammograms. Relations between charge densities and potentials were deduced from data of the voltammograms. A shift in peak potential for the anodic current transient from $E=20 \mathrm{mV}$ to $E=-2 \mathrm{mV}$ was observed after completion of four subsequent cycles of copper electrodeposition/dissolution. The shift is suggested to be equal to the change in potential of the working electrode owing to the formation of the alloy phase.

\section{Introduction}

In recent investigations of copper electrocrystallization the growth on clean noble metal surfaces has been studied in detail by in situ scanning tunneling microscopy (STM) from the formation of underpotential deposited (UPD) monolayers, ${ }^{1-5}$ initial nucleation and growth of nuclei by 3 -D growth, ${ }^{7-11}$ technological processes, ${ }^{12,13}$ and influence of additives ${ }^{11,14}$ to the effect of electrocrystallization by pulse plating. ${ }^{13}$ Due to the unique resolution of the microscope most of the electrochemical investigations has been directed toward studies at the atomic level.

In the present work it was demonstrated that in situ STM reveals properties of the copper-gold interface formed by potentiostatic copper electrodeposition studied at an intermediate level of magnification, i.e., in the range of magnifications (submicron level) inaccessible to scanning electron microscopy (SEM) and below atomic resolution. The morphology of the clean native polycrystalline gold (pc Au) surface roughened by cycles of potentiostatic copper electrodeposition and subsequent dissolution. A major transformation of the pc Au surface was observed after the first cycle and minor transformations owing to growth of an alloy phase were observed in subsequent cycles. The growth was followed by in situ STM in a stepwise manner, and the growth of the alloy phase was found to occur both during the period of copper electrodeposition and during the period of copper electrodissolution. The formation of the alloy phase can be explained in terms of existing models of gold atom mobility. ${ }^{15-23}$ By comparing simultaneous recordings of current transients with the amount of alloy formed within the frame of the in situ STM image, it is suggested that the copper content was less than 10 atom percent $(\mathrm{a} / \mathrm{o})$. The initial changes observed in voltammograms during the first cycles of copper electrodeposition/dissolution are thus explained as a concomitant change of surface morphology. A power law dependence is deduced by voltammetry methods which relates the charge density to the change in potential of the working electrode.

\section{Experimental}

The in situ STM measurements were carried out at room temperature in an open cell by a commercially available system (Rasterscope $3000^{\mathrm{TM}} / \mathrm{EC}$, Danish Micro Engineering A/S, Denmark) which allows simultaneous image acquisition and electrochemical data acquisition. A separate PC controls the electrochemistry via a bipotentiostat (ECRasterscope $3000^{\mathrm{TM}}$, Danish Micro Engineering $\mathrm{A} / \mathrm{S}$ ) and interface. In order to minimize noise from the main power supply's influence on the tunneling current, the bipotentiostat can be switched to a battery powered mode which greatly enhances the quality of the images as well as the quality of the voltammograms. With this system special electrochemical experiments such as in situ studies of galvanostatic pulse plating and potentiostatic pulse plating can be carried out by user-defined routines. ${ }^{13}$ The piezoelectric scanning unit and the electrochemical cell were sealed off from their surroundings by a glass bell jar, and the humidity was kept at a maximum by saturating the atmospheric air with water vapor so as to prevent evaporation of the electrolyte.

Gold films (thickness, $0.2 \mu \mathrm{m}$; area, $0.5 \mathrm{~cm}^{2}$ ) vacuum evaporated onto glass (Berliner Glass) were utilized as working electrodes. The electrochemical cell consisted of a Teflon-coated Viton O-ring which was mechanically pressed against the gold film producing a cell volume of $150 \mu \mathrm{l}$. The counterelectrode was a $1 \mathrm{~mm}$ Pt wire and the (pseudo)reference electrode was a $0.2 \mathrm{~mm} \mathrm{Cu}$ wire. Prior to the experiment the gold films were flushed in $0.5 \mathrm{M}$ sulfuric acid and in Millipore water. All chemicals used were of the highest purity available. The electrolyte was $0.01 M$ sulfuric acid with $0.01 M$ copper sulfate in Millipore water which was kept at room temperature. The potential sweeps were carried out from $E=+500 \mathrm{mV}$ to $E=-100 \mathrm{mV}$ and back to $E=+500 \mathrm{mV}$ at a sweep rate of $1 \mathrm{mV} / \mathrm{s}$.

The STM tips were coated by the electropaint method developed by Bach et al. ${ }^{24}$ which readily yielded coatings producing tip-faradaic currents of 1 pA or less measured at a fixed potential in the bipotentiostat battery-powered mode. The faradaic current was kept in the picoampere range and the images were acquired at a tunneling current of 1 to $2 \mathrm{nA}$.

\section{Results and Discussion}

The recently developed methods of in situ STM/atomic force microscopy (AFM) and related scanning methods (generally referred to as in situ SPIM) ${ }^{12}$ offer unique possibilities for imaging electrochemistry in real time..$^{1-11,25}$ Any alterations of the electrode morphology down to the atomic level can be imaged by these techniques. ${ }^{1-6}$ Metal surface working electrodes are frequently subjected to pretreatments of cyclic voltammetry which ensure reproducibility of subsequent measurements. In the following paragraphs the morphology of the native pc Au surface is examined by imaging at the submicron level of magnification and the image features are correlated with voltammetry.

Recrystallization of the native gold surface due to cycles of copper electrodeposition and subsequent dissolution.As the structure of gold surfaces are sensitive to potential changes both with ${ }^{26}$ and without ${ }^{15-17}$ metal ions in the electrolyte the potential was fixed initially at $E=500 \mathrm{mV}$. At this potential no reconstruction or oxidation of the surface are expected, and the copper ions do not deposit. Thus, images of the clean gold surface resemble corresponding images acquired in air or vacuum. The pc Au surface con- 


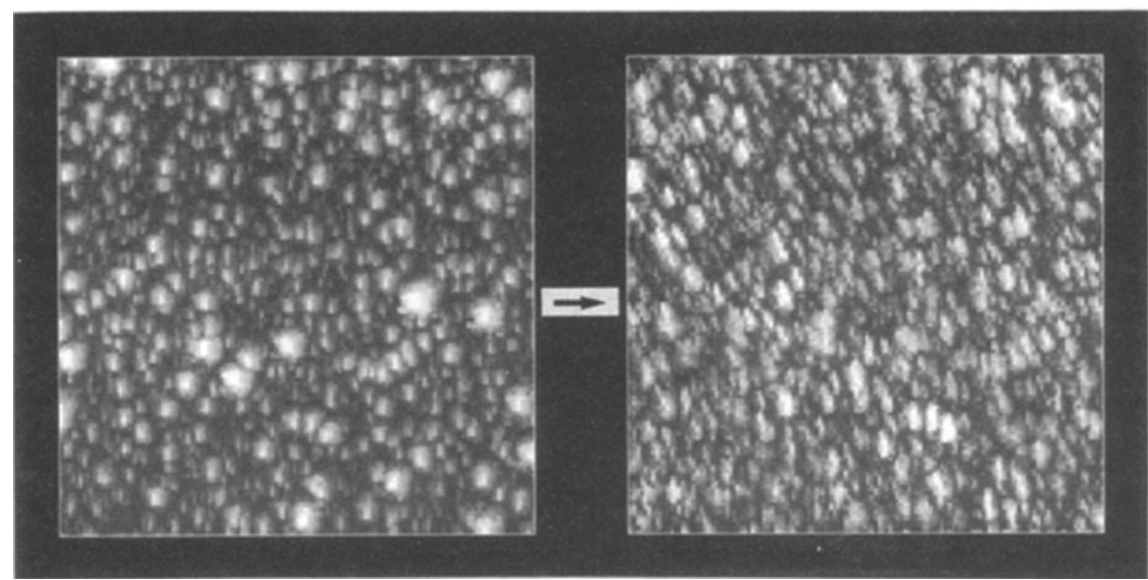

\section{7 micron}

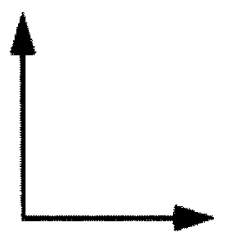

1.7 micron

Fig. 1. In situ STM images of the clean gold surface obtained in an acidified copper sulfate electrolyte $10.01 \mathrm{M} \mathrm{H}_{2} \mathrm{SO}_{4}, 0.01 \mathrm{MCuSO}_{4}, \mathrm{Millipore}$ water) at $E=500 \mathrm{mV}$ and $E_{\mathrm{t}}=542 \mathrm{mV}$. (a) Clean pc Au surface which had never been exposed to copper electrodeposition ( $z=45 \mathrm{~nm}$ ). (b) The same surface as imaged in (a) but recorded after it had been recrystallized due to the first cycle of bulk copper electrodeposition and subsequent dissolution $(z=34 \mathrm{~nm})$.

sisted of hemispherical clusters with characteristic diameters varying from 10 to $100 \mathrm{~nm}$ (Fig. 1a-b) as confirmed by AFM measurements. ${ }^{27}$ If the gold ciusters of Fig. 1a and $b$ are considered to be approximately hemispherical in shape, the effective area of the working electrode is estimated to be twice the size of the geometrical area. In order to demonstrate the effect of copper deposition on the morphology of the clean gold surface one cycle of copper electrodeposition and subsequent dissolution was carried out. After the dissolution of copper, the morphology changed from the one shown in Fig. 1a to the morphology shown in Fig. 1b. Some of the gold clusters of Fig. 1a have decreased in size and some have increased in size so as to form a surface of gold crystallites with a more uniform distribution of dimensions (Fig. 1b). The change in morphology from Fig. 1a to Fig. 1b is characterized by spherical clusters crystallizing into crystallites of a rectangular shape and the surface becoming more planar ( $z=45 \mathrm{~nm}$ in Fig. $1 \mathrm{a}$ and $z=34 \mathrm{~nm}$ in Fig. 1b. Crystalline gold surfaces are known to deteriorate after some weeks of use in experiments with bulk copper electrodeposition. ${ }^{7}$ Thus, possibly the transformation observed after the first cycle of copper deposition (Fig. 1a and b) is due to the formation of an alloy. All the images of Fig. $1 \mathrm{a}$ and $\mathrm{b}$ and $2 \mathrm{a}-\mathrm{d}$ are acquired at $E=500 \mathrm{mV}$. At a higher magnification more details in surface morphology are revealed after the first cycle of bulk copper electrodeposition/dissolution as shown in Fig. $2 a$ and b. The small gold clusters in Fig. 2a merge and form large areas of the alloy phase (Fig. 2b). The hemispherical structure of the gold clusters in Fig. $2 a$ was succeeded by a more planar structure with steps and terraces (Fig. 2 b). On the top sites of the surface topography small nuclei of the alloy phase had crystallized and separated by up to hundreds of nanometers (Fig. 2b). Most of the alloy nuclei are cubic in shape but some of the large nuclei have developed into a triangular shape (Fig. 2b). In order to obtain reproducible voltammetry the gold electrode is subjected to repetitive potential sweeps. The potential sweep methods are commonly applied to experiments of copper electrodeposition on various surfaces ${ }^{18-20,28}$ which may be ascribed to a surface cleansing. In view of the present work the pretreatment results in a change of morphology rather than a cleaning of the surface.

It has been shown by Nichols et al. ${ }^{15}$ that rearrangements of surface atoms by surface diffusion owing to potential changes occur even in the double-layer charging region on the gold surface in sulfuric acid electrolytes. The growth of gold islands is related to a transition from a less dense to a more dense surface structure which forces the atoms upwards, and they subsequently coalesce into islands by surface diffusion. Reconstruction of the gold surface can occur due to specific adsorption of anions as shown by Kolb and Schneider ${ }^{28}$ and an overall adsorption strength of anions has been suggested by Borkowska and Stimming ${ }^{29}: \mathrm{Cl}^{-}>$ $\mathrm{HSO}_{4}^{-}>\mathrm{OH}^{-}>\mathrm{ClO}_{4}^{-}$. In the presence of underpotentially deposited copper adatoms Shi and Lipkowski showed that the adsorption of sulfate anions is enhanced. ${ }^{30}$ The role of the adsorbing anions in the surface atoms mobility is not fully elucidated, but it has been suggested that the anion donation of electrons destabilizes the interatomic bonds of surface atoms with a concomitant surface relaxation and increase of atomic mobility. ${ }^{6,20}$ In electrolytes free of copper ions the change of surface roughness in electrodispersed metal electrodes has been studied by ex situ methods. ${ }^{18-20}$ Potential sweep methods allow the determination of surface diffusion coefficients at fixed potentials, ${ }^{18,19}$ and it has been proposed that the gold-water interactions are controlling factors of surface atom mobility. ${ }^{20}$

Growth of the copper-gold alloy phase.-By carrying out a second cycle of copper deposition/dissolution the nuclei of Fig. $2 b$ increased in size and developed into characteristic triangular shaped crystallites (Fig. 2c). Underneath the triangular shaped crystallites a base also grew out from the surface (Fig. 2c). This base developed further after a third cycle of copper deposition/dissolution and after the fourth cycle characteristic "butterfly-like" shaped crystallites were formed (Fig. 2d). In Fig. 3 is illustrated schematically how the shape of the crystallites change after completion of four cycles. The "butterfly" crystals did not dissolve even after $1 \mathrm{~h}$ at $E=700 \mathrm{mV}$, i.e., they cannot consist of a pure copper phase.

In order to elucidate in detail the mechanism of crystallite growth the copper deposition was imaged as a function of (low) cathodic overpotentials as shown in Fig. 4a-d. The images of Fig. $2 \mathrm{~b}$ and $4 \mathrm{a}$ are from the same area on the surface, but $E=500$ and $E=0 \mathrm{mV}$ for the two images, respectively. The effect of sweeping the potential from $E=$ 500 to $E=0 \mathrm{mV}$ was observed as a slight increase of dimensions of the crystallites already formed on the surface (Fig. 4a). Upon a sweep in potential to $E=-30 \mathrm{mV}$ many of the crystallites grew in size, and a few new crystallites were identified as shown in Fig. $4 \mathrm{~b}$. At $E=-40 \mathrm{mV}$ all the crystallites had more than doubled their dimensions as compared to Fig. 4a and many new crystallites were formed (Fig. 4c). After about $5 \mathrm{~min}$ at $E=-40 \mathrm{mV}$ the surface was completely covered with copper crystallites whose dimensions are $30 \mathrm{~nm}$ which is characteristic of crystallites grown at low cathodic overpotentials. ${ }^{9,26}$ Although the gold surface was covered with copper crystallites, it was still possible to recognize the crystallites of Fig. $4 \mathrm{a}$ in the image of Fig. 4d. From an analysis of all the images acquired in the 


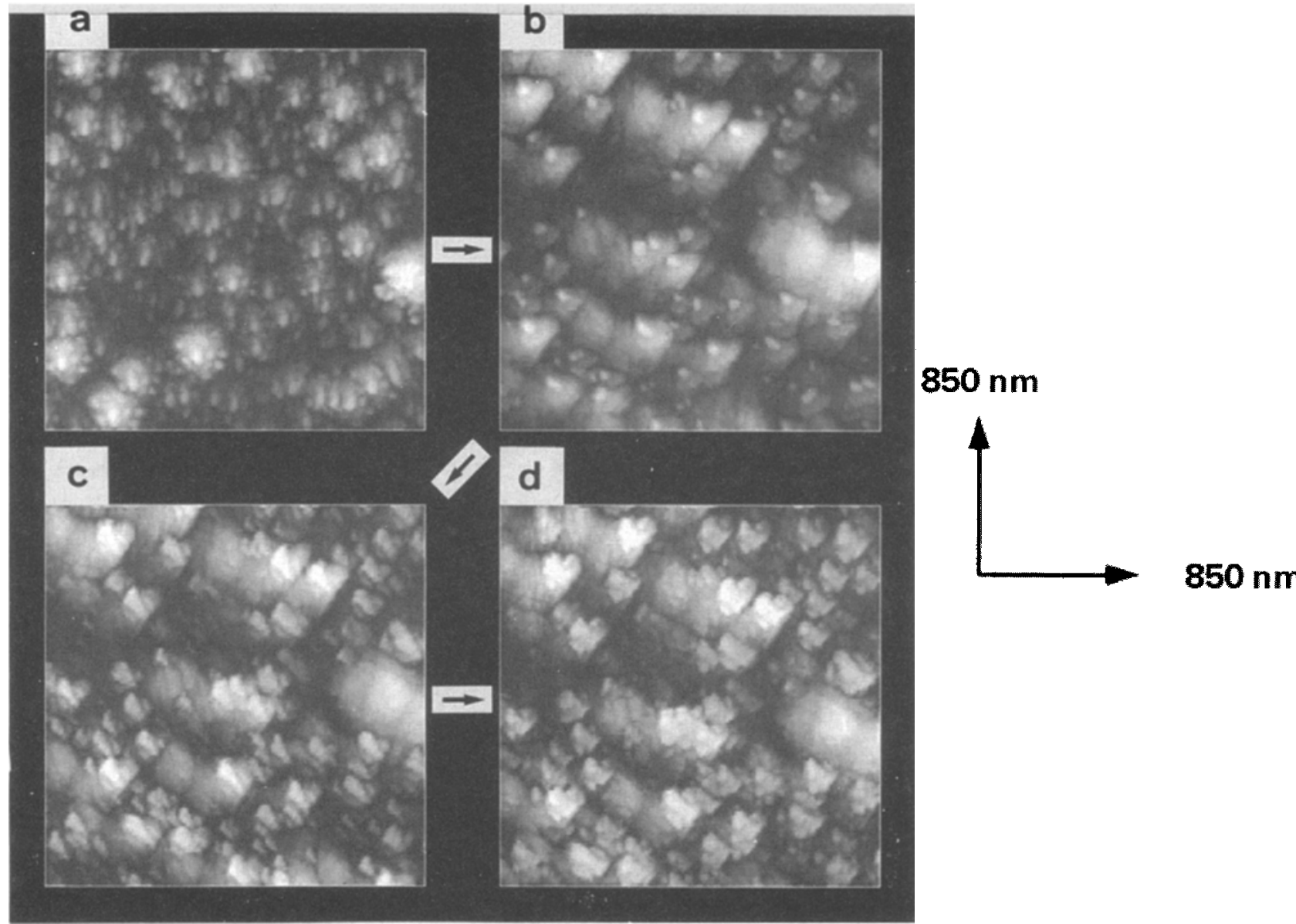

Fig. 2. Development in morphology of the gold surface due to cycles of bulk copper electrodissolution imaged by in situ STM. Electrolyte: $0.01 \mathrm{M} \mathrm{H}_{2} \mathrm{SO}_{4}, 0.01 \mathrm{M} \mathrm{CuSO}_{4}$, Millipore water. The images were recorded at $E=500 \mathrm{mV}$ and $E_{\mathrm{f}}=542 \mathrm{mV}$. (a) The clean gold polycrystalline surface before any copper electrodeposition was carried out $(z=48 \mathrm{~nm})$. (b) Recrystallized gold surface with alloy nuclei (light spots) obtained after completion of the first cycle $(z=37 \mathrm{~nm})$. (c) Recrystallized gold surface with alloy crystallites observed after completion of the second cycle $(z=35 \mathrm{~nm})$. (d) Recrystallized gold surface with alloy crystallites observed after completion of the fourth cycle $(z=35 \mathrm{~nm})$.

experiment of Fig. $4 a-d$, it was found that the $z$-scale, i.e., essentially the average thickness of the crystallites perpendicular to the surface, increased linearly with time. It was deduced that the $z$-scale of the images increased with a rate of $0.020 \pm 0.005 \mathrm{~nm} / \mathrm{s}$. Because the surface was covered with copper and some of the alloy features were still visible the total amount of copper on the surface may be estimated. From Fig. $4 a-d$ and $5 a-d$ and the change of the $z$-scale with time, it was found that the average thickness of the copper layer was $15 \pm 2 \mathrm{~nm}$ which corresponds to $7 \%$ of the copper from the electrolyte residing on the surface (assuming bulk density). Accordingly, the potential of the $\mathrm{Cu} / \mathrm{Cu}^{2+}$ reference electrode remained constant. By dissolving the copper it was observed how the growth of the alloy crystallites proceeded (Fig. 5a-d). The nuclei in Fig. 4a had grown in size during the period of deposition due to copper adatoms adsorbing predominantly to nuclei (Fig. 4b-d and 5a). During the period of dissolution the dimensions of the nuclei further increased, and at $E=30 \mathrm{mV}$ they displayed their final shape (Fig. $5 \mathrm{c}$ ). When all the copper was dissolved, the nuclei of Fig. 4a had grown into triangular crystallites as shown in Fig. 5d. About double the number of crystallites are identified in the image of Fig. $5 \mathrm{~d}$ as compared to the number of nuclei in Fig. 4a. This is probably due to smaller nuclei of Fig. 4a growing in size, so as to become visible in Fig. 5a.

The number of nuclei in Fig. $2 \mathrm{~b}$ is approximately 80 which yields a surface density of $10^{10} \mathrm{nuclei} / \mathrm{cm}^{2}$. This surface density of nuclei is thus two- to three-orders of magnitude greater than the total Gibbs excess of sulfate ions determined in perchloric solution ${ }^{30}$ with, however, lower concentrations of sulfate and copper ions. Although strictly not comparable, but taking into account differ- ences in concentrations, the number of nuclei in Fig. $2 \mathrm{~b}$ might be associated with the presence of adsorbed sulfate anions. Very high diffusion constants of gold surface diffusion $\left(D_{\mathrm{S}}=10^{-12} \mathrm{~cm}^{2} / \mathrm{s}\right)$ have been determined both by ex situ methods ${ }^{21,22}$ and by in situ $\mathrm{STM}^{23}$ during the dealloying of copper/gold alloys with a low amount of gold content. Clustering of gold atoms occur on these surfaces near sites of copper dissolution at low overpotentials as monitored in real time experiments. ${ }^{23}$ As a protective layer of gold forms further dissolution of copper is inhibited in the corrosion process. ${ }^{21}$ These are the basic mechanisms controlling the formation of a surface alloy on the pc Au surface (Fig. 2b-d) because they explain that diffusion gold atoms actually may prevent copper from dissolving.

Voltammetry.-Because the process of electrodeposition and dissolution was carried out at a low potential sweep rate and because the tip was well coated, it was possible to simultaneously acquire images and voltammograms. Accordingly, all peaks in the voltammogram may be directly compared with features of the images which facilitates the interpretation of the electrode process. ${ }^{31,32}$

Characteristic voltammograms recorded consecutively at a potential sweep rate of $1 \mathrm{mV} / \mathrm{s}$ for bulk copper deposition and dissolution are shown in Fig. 6. All four voltammograms of Fig. 6 show different current transients which reveal an irreversible behavior of the system. The voltammograms may be characterized by the following three features.

1. The onset of copper electrodeposition shifts toward higher potentials as a function of cycle number. When the potential $(E)$ reaches $E \sim-60 \mathrm{mV}$ (sweeping from positive potentials), the cathodic current starts to rise at the onset of 
copper electrodeposition. In the in situ STM image the surface was covered with copper at the point where the current starts to rise. ${ }^{26}$ By depicting the onset $\left(E_{0}\right)$ of rise in cathodic current as a function cycle number $(N)$ a linear dependence is found as shown in Fig. 7. Fitting a straight line by least squares to the data of Fig. 7 yields

$$
E_{O}=-3.3 \cdot N-62 \mathrm{mV}
$$

Thus, every cycle results in a $-3.3 \mathrm{mV}$ shift in potential for the onset of electrodeposition. If the system was ideally reversible, the slope of the straight line of Fig. 7 would be zero. The intercept of the line is $-62 \pm 1 \mathrm{mV}$ which may be interpreted as the potential of the onset of copper elec-

\section{First cycle}
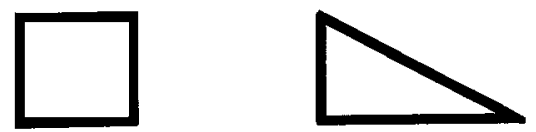

\section{Second cycle}

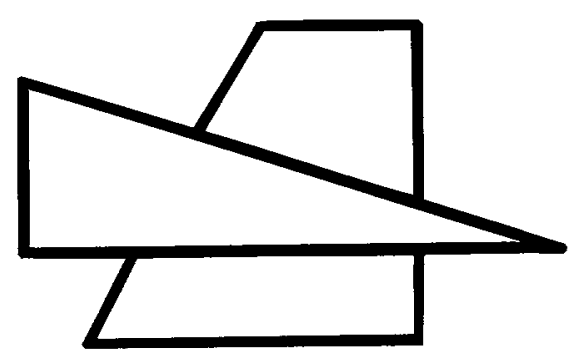

\section{Fourth cycle}

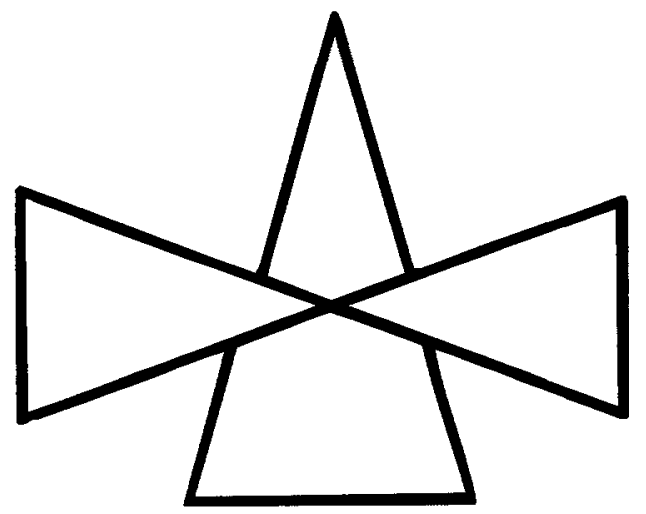

Fig. 3. Schematic diagram of the development of crystallites shape (see Fig. 2b-d) after four subsequent cycles of potentiostatic bulk copper electrodeposition/dissolution at a sweep rate of $1 \mathrm{mV} / \mathrm{s}$. The initially grown nuclei (first cycle) were square or triangular in shape with no basis. After completion of the second cycle the basis of the crystallite was recognized, and affer the fourth cycle the crystallites exhibited a characteristic "butterfly-like" shape. trodeposition for an ideal reversible system. From Eq. 1 it can be seen that the potential of onset shifted by $-13 \mathrm{mV}$ after completion of four cycles.

2. The anodic part of the current transient show a shift in peak position from $E=20$ to $E=-2 \mathrm{mV}$. The position of the peak potential $\left(E_{P}\right)$ of the anodic current is shown in Fig. 8 as a function of $N$. With $E_{\text {alloy }}$ being the peak potential of the alloy-covered surface it is assumed that the change of $E_{\mathrm{P}}$ with respect to the change in cycle number $N$ is proportional to the peak potential, i.e:

$$
\frac{d E_{\mathrm{P}}}{d N}=c_{\mathrm{P}} \cdot E_{\mathrm{P}}
$$

where $c_{\mathrm{P}}$ is a constant. With the limits $E_{\text {gold }}-E_{\text {alloy }}$ and $E-$ $E_{\text {alloy, }}$, where $E_{\text {gold }}$ is the peak potential of the clean gold surface, integration of Eq. 2 yields

$$
E_{\mathrm{P}}=E_{\text {alloy }}+\left(E_{\text {gold }}-E_{\text {alloy }}\right) \cdot \exp \left(c_{\mathrm{P}} \cdot N\right)
$$

Thus, $E(N=0)=E_{\text {gold }}$ and $E(N \rightarrow \infty)=E_{\text {alloy }}$ when $c_{\mathrm{P}} \leq 0$. The line which connects the points in Fig. 8 is a fit of the data to the function of Eq. 3. The values of the constants of Eq. 3 are thus: $c_{\mathrm{P}}=-1.2 \pm 0.1$ cycles $^{-1}, E_{\text {alloy }}=-2.6 \pm 0.3 \mathrm{mV}$, and $E_{\text {gold }}=69 \pm 8 \mathrm{mV}$. Accordingly, the potential of anodic dissolution of copper changes by $72 \pm 8 \mathrm{mV}$ during the first four cycles.

3 . The areas change as a function of $N$ under the curves of the current transients. The most distinct change occurs between the first and the second cycle; all areas under the curve of the first cycle, cathodic as well as anodic, are large as compared to areas of voltammograms recorded subsequently. In Fig. 6 three areas are considered which are proportional to the charge density $(Q)$. The first area is situated under the curve when $E$ is swept between $E=100 \mathrm{mV}$ to $E=-100 \mathrm{mV}$ (Fig. 6 and 9 a), the second is the area from $E=-100 \mathrm{mV}$ to the potential where the current density is zero [Fig. 6 and $9(\boldsymbol{\Delta})$ ] and the third area is the area of the anodic peak [Fig. 6 and $9(\bullet)$ ]. It is assumed that the change in charge density $(|Q|)$ required to deposit and subsequently dissolve the copper with respect to the change in number of cycles is proportional to the charge density, hence

$$
\frac{d|Q|}{d N}=c_{Q} \cdot|Q|
$$

with $c_{Q}$ being a constant. Integration of Eq. 4 with the limits from $Q_{\text {gold }}-Q_{\text {alloy }}$ to $Q-Q_{\text {alloy }}$ (with the same notation as in Eq. 2 and 3) yields

$$
|Q|=Q_{\text {alloy }}+\left(Q_{\text {gold }}-Q_{\text {alloy }}\right) \cdot \exp \left(c_{Q} \cdot N\right)
$$

Then, $|Q|(N=0)=Q_{\text {sold }}$ and $|Q|(N \rightarrow \infty)=Q_{\text {alloy }}$ for $c_{Q} \leq 0$. By fitting the data of Fig. 9a to Eq. 5 the values of $Q_{\text {alloy }}, Q_{\text {gold }}$, and $c_{Q}$ are obtained as presented in Table I. From the constants of Table I it was found that $Q_{\text {gold }} / Q_{\text {ailoy }}=2.7 \pm 0.3$, i.e., when copper was electrodeposited/dissolved on the clean gold surface almost three times the charge flow as compared with the charge flow to the alloy-covered surface. The data fit very well the function of Eq. 5, and it may therefore be suggested that three different faradaic processes are involved in the copper electrodeposition/dissolution. The difference in charge density of electrodeposition and dissolution is illustrated in Fig. 9b. For $N<1$ the difference in charge density is positive which suggests that no copper was deposited. In Fig. 9a there is a small but significant difference between the first and second (cathodic) areas. For $N>0.9$ it is seen in Fig. 9a that the charges $\left|Q_{1}\right|$ and $\left|Q_{2}\right|$ which correspond to areas No. 1 and 2 , respectively, in Fig. 6 obeys $\left|Q_{1}\right|>\left|Q_{2}\right|$. Similarly, $\left|Q_{1}\right|>\left|Q_{3}\right|$ for $N>$ 1 (Fig. 9b). Clearly, the charge densities of Fig. 9a do not balance, i.e., the anodic charge is different from the cathodic charge. In these experiments there is an excess of cathodic charge which can be estimated from Fig. $9 \mathrm{~b}$. The total amount of excess charge density $(\Delta Q)$ for $1 \leq N \leq 4$ is (Fig. 9b): $\Delta Q=\sum_{N=1}^{4}\left(\left|Q_{3}\right|-\left|Q_{1}\right|\right)_{N}=-4400 \mathrm{mC} / \mathrm{cm}^{2}$, which is calculated using the geometrical area. By using the estimated effective area of the working electrode (see sections above) the excess charge density is $\Delta Q \cong-2200 \mathrm{mC} / \mathrm{cm}^{2}$. 


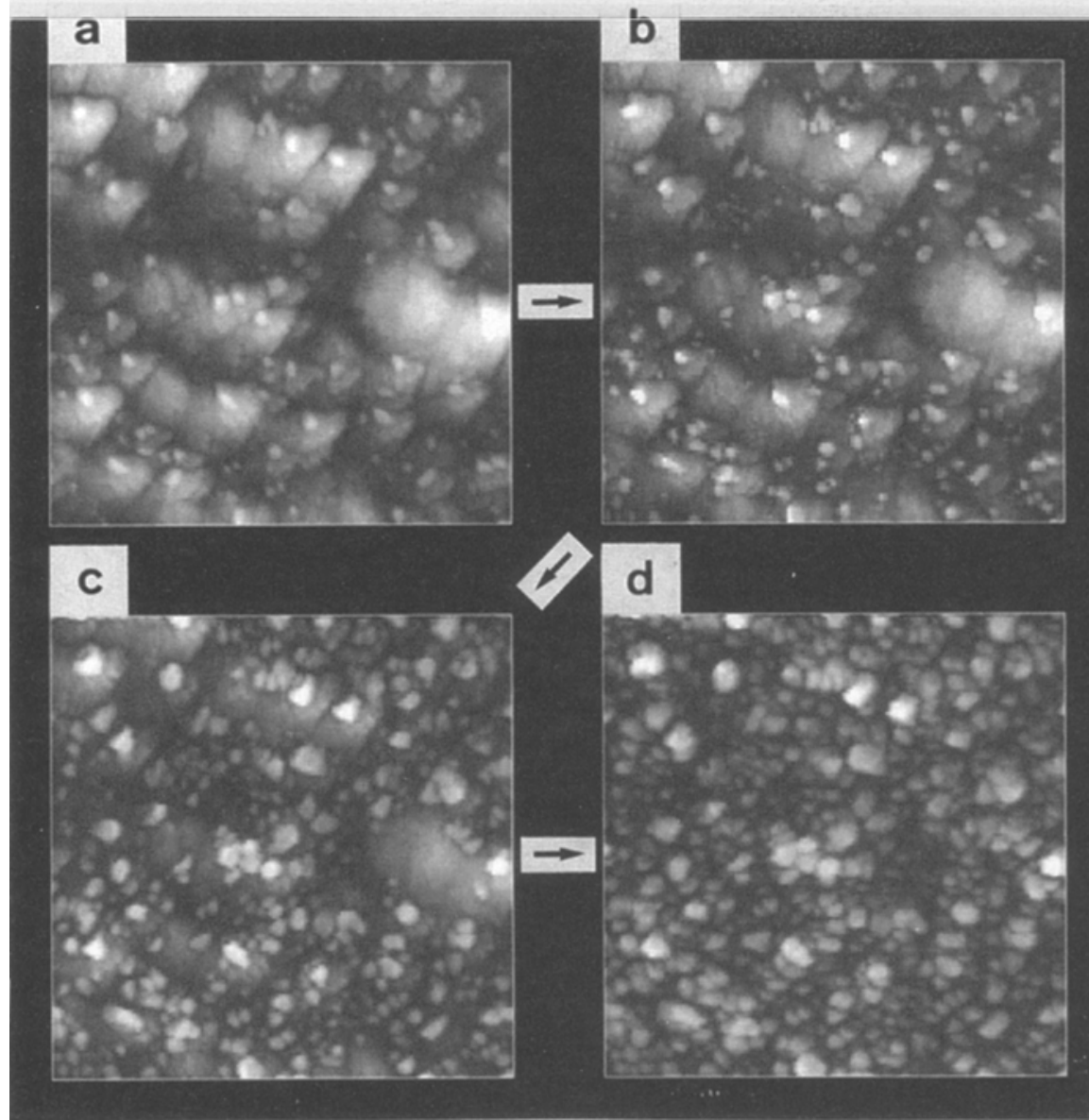

\section{$850 \mathrm{~nm}$}

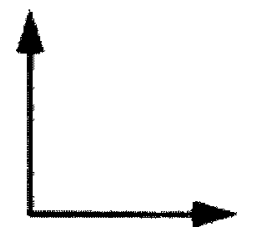

$850 \mathrm{~nm}$

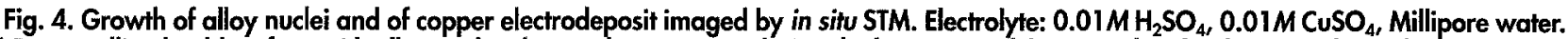
(a) Recrystallized gold surface with alloy nuclei observed at $E=0 \mathrm{mV}$ during the beginning of the second cycle of copper electrodeposition/dissolution $(z=37 \mathrm{~nm})$. (b) Increase in dimensions of alloy nuclei owing to copper nucleation, $E=-30 \mathrm{mV}(z=39 \mathrm{~nm})$. (c) Growth of alloy nuclei and of copper clusters, $E=-40 \mathrm{mV}(z=46 \mathrm{~nm})$. (d) Copper clusters and alloy crystallites covering the surface, $E=-45 \mathrm{mV}(z=52 \mathrm{~nm})$.

The effective area is expected to be underestimated by this method because pits and cracks in the surface are unaccounted for. However, it may be comparable to effective areas determined by Au oxidation voltammetry which are also underestimated as shown by Vitus and Davenport. ${ }^{33}$

By comparing Eq. 3 and 5 it is found that the charge density $(Q)$ depends on the peak potential $(P)$ as

$$
Q=Q_{\text {alloy }}+\left(Q_{\text {gold }}-Q_{\text {alloy }}\right) \cdot\left|\frac{E-E_{\text {alloy }}}{E_{\text {gold }}-E_{\text {alloy }}}\right|^{\frac{c Q}{c_{P}}}
$$

for $E_{\text {alloy }} \leq E \leq E_{\text {gold }}$.

Image analysis.-From the images of Fig. 2 the exact dimensions of alloy crystallites and the distribution of dimensions can be evaluated. Because the entire basis of the gold surface was recrystallized during the first cycle of copper electrodeposition (Fig. 2b) and because it did not change during subsequent cycles only the dimensions of nuclei and crystallites are considered in the following analysis. By measuring the surface areas of the crystallites the area distribution of nuclei of Fig, $2 b$ was evaluated as shown in Fig. 10a. Alloy nuclei and crystallites with areas below $500 \mathrm{~nm}^{2}$ were prevailing on the surface after the first cycle (Fig. 10a). After the second cycle the small nuclei were not prevailing on the surface. Their areas had grown in size and a wide distribution of crystallite sizes peaking at $1500 \mathrm{~nm}^{2}$ was formed (Fig. 2c and 10b). After completion of the fourth cycle (Fig. 2d) the distribution of areas peaked at $5000 \mathrm{~nm}^{2}$, and there was a large number of crystallites with areas less than $1000 \mathrm{~nm}^{2}$ as shown in Fig. 10c. The total volume of the alloy phase including all nuclei and crystallites grown from Fig..2b to Fig. $2 \mathrm{~d}$ is $2.9 \cdot 10^{6} \mathrm{~nm}^{3}$ as deduced by a height and area analysis of crystallites observed in Fig. 10a to $c$. If it is assumed that the crystallites in Fig. $2 \mathrm{~b}$-d were grown of pure copper of bulk density the amount of charge density to grow $2.9 \cdot 10^{6} \mathrm{~nm}^{3}$ corresponds to approximately $2.2 \cdot 10^{4} \mathrm{mC} / \mathrm{cm}^{2}$ (assuming a copper valence of 2) which is an order of magnitude larger than the actual charge passed as deduced by the voltammetry (above). Thus, the crystallites of Fig. 2 did not consist of pure copper but possibly of a copper-deficient gold alloy with a copper-to-gold ratio of less than 1:10 which is consistent with the findings of Fritz and Pickering. ${ }^{21}$ They suggest that the copper content in a protective gold layer formed by de-alloying of a copper-gold alloy surface is 5 to 15 atom percent $(\mathrm{a} / \mathrm{o})$. Because other faradaic processes are involved according to Fig. 9a the copper content may be even less. This is supported by the observation that the crystallites did not grow exclusively during the sweep from anodic potentials toward cathodic potentials (Fig. $4 a-d$ ) but also when the copper was dissolved as shown in Fig. 5a-d (see the previous section for an explanation of mechanism).

The irreversible change of surface morphology by the cycles of copper electrodeposition associated with shifts in peak potential (see above) and in charge densities shows that copper electrodeposition is a more subtle process as compared to what have been understood previously. ${ }^{9,11,13,26,28,34}$ By the description of the change in peak potential ( $E_{\mathrm{p}}$ ) (above and Fig. 8) it may be suggested that the potential of the gold changed irreversibly owing to the surface recrystallization and growth of crystallites. Thus, the shift in peak potential may be interpreted as a shift in working electrode potential, i.e., $\Delta E_{\mathrm{P}}=\Delta E_{\mathrm{W}}$.

Potentiostatic bulk copper electrodeposition onto crystalline gold surfaces results in an instantaneous nucleation around surface defects (including step, kinks, etc.). ${ }^{7-9}$ The number of nuclei depends on the size of the overpotential and the copper grows into islands ${ }^{7-9}$ and crystallites ${ }^{11}$ dur- 


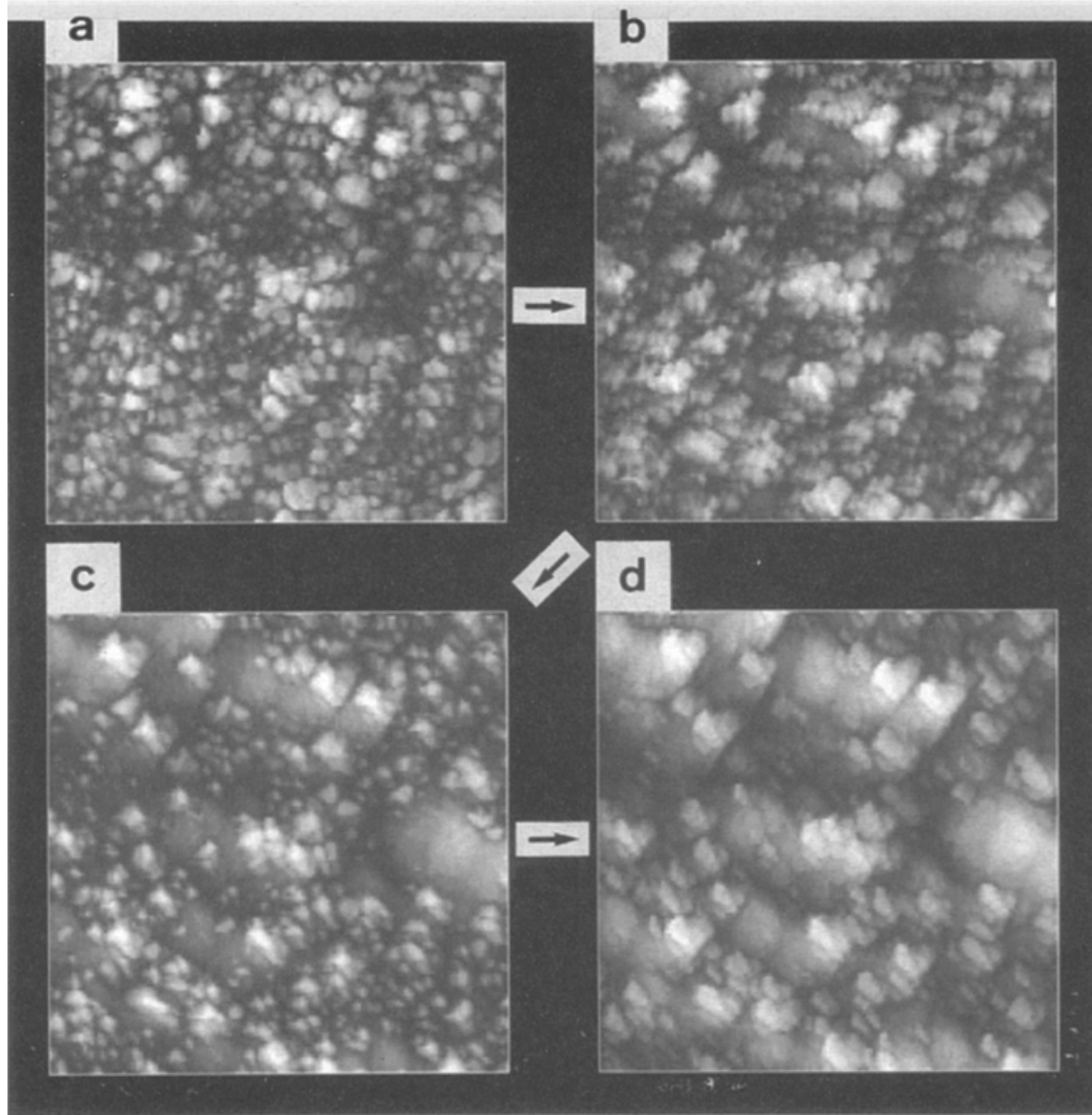

\section{$850 \mathrm{~nm}$}

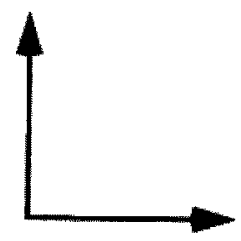

$850 \mathrm{~nm}$

Fig. 5. Potentiostatic dissolution of bulk copper electrodeposited on gold imaged by in situ STM. Electrolyte: $0.01 \mathrm{M} \mathrm{H}_{2} \mathrm{SO}_{4}, 0.01 \mathrm{M} \mathrm{CuSO}_{4}$, Millipore water. (a) Copper clusters and alloy crystallites covering the gold surface at $E=-55 \mathrm{mV}(\mathrm{z}=49 \mathrm{~nm})$. (b) Dissolving copper clusters and growing alloy crystallites on the gold surface at $E=25 \mathrm{mV}(z=43 \mathrm{~nm})$. (c) Alloy crystallites and remaining copper clusters at $E=30 \mathrm{mV}$ $(z=42 \mathrm{~nm})$. (d) Alloy crystallites with triangular shape formed on top of the recrystallized gold surface, $E=500 \mathrm{mV}(z=35 \mathrm{~nm})$.

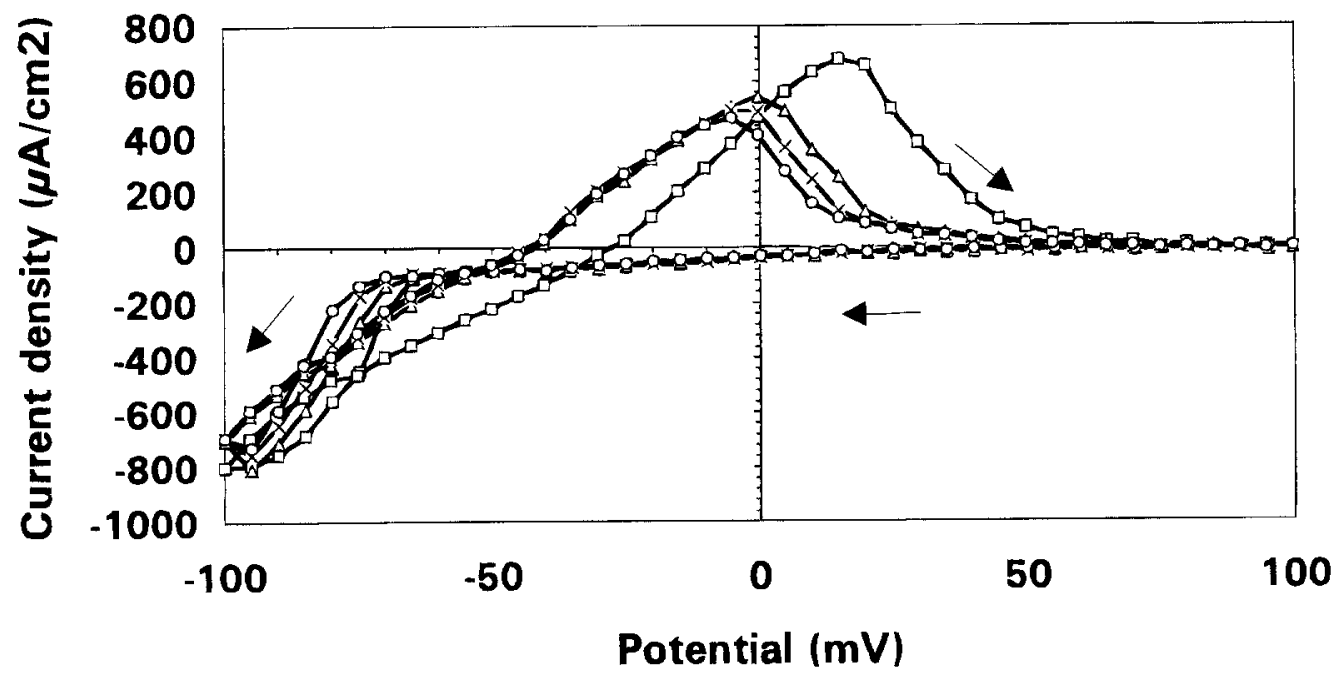

Fig. 6. Change of voltammograms during the first four cycles of bulk copper electrodeposition and subsequent dissolution on gold recorded at a potential sweep rate of $1 \mathrm{mV} / \mathrm{s}$ simultaneously with in situ STM image acquisition. The measurements were carried out in an acidified copper sulfate electrolyte $\left(0.01 \mathrm{M} \mathrm{H}_{2} \mathrm{SO}_{4}, 0.01 \mathrm{M} \mathrm{CuSO}_{4}\right.$, Millipore water). (The arrows indicates the direction of potential sweep).

ing further growth at a fixed overpotential. Under the influence of organic additives the copper growth also occurs by an initial nucleation at surface defects followed by a coalescence of islands owing to a preferential lateral growth. ${ }^{7,12}$ Bulk copper electrodeposition on crystalline Pt shows a similar initial nucleation process with the number of crystallites being dependent on the size of the overpotential. ${ }^{31,34}$ On the Pt substrate the additives induce a decrease in particle size which is comparable to the process of cop- per pulse plating onto gold by applying $20 \mathrm{~ms}$ periods of cycling time. ${ }^{13}$ It has been suggested recently that coadsorption of hydrogen occurs in combination with the copper electrodeposition ${ }^{26}$ which adds to the complexity of copper electrodeposition/dissolution. Therefore, the faradaic processes extracted above (Fig. 9a and b) possibly involves copper oxidation/reduction, hydrogen adsorption/ desorption and alloy formation. Tentatively, if hydrogen adsorbs right from the initial stages of copper electrodepo- 


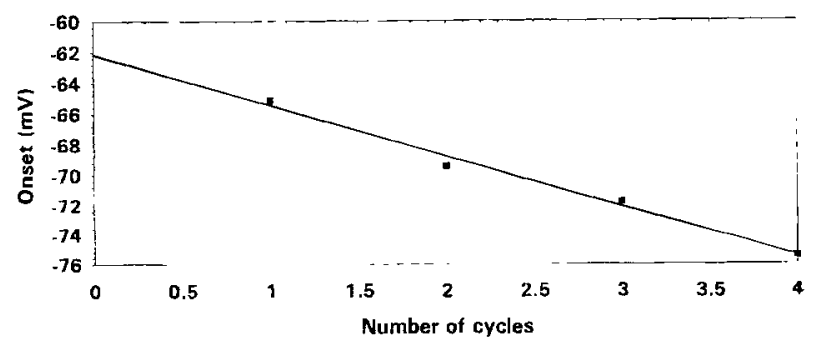

Fig. 7. Potential of onset of copper electrodeposition on gold (Fig. 6) depicted as a function of cycles. The straight line was fitted to the data by least squares.

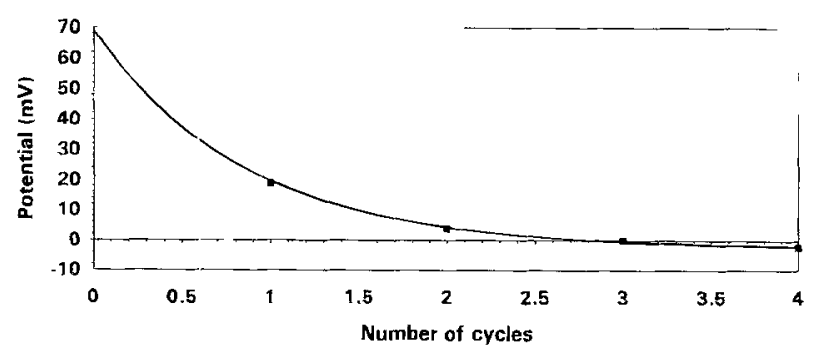

Fig. 8. Shiff in peak potential for the anodic current transient (Fig. 6) as a function of cycles of bulk copper electrodeposition/dissolution on gold. An exponential function was fitted to the data (full line) (see text for detrils).

sition this mav explain why copper forms islands and does not merge at low cathodic overpotentials (Fig. 4b-d), viz. hydrogen adsorbed on the surface of copper nuclei forms a barrier between the nuclei which prevents surface diffusion.

Subsequent to a cycle of copper electrodeposition/dissoIution the original area of the crystalline gold surface was recovered and at the atomic level ${ }^{7-9}$ or the near atomic level the gold surfare seemed to be unaffected by the process. ${ }^{26}$ Cycles of copper electrodeposition/dissolution by underpotential deposition seem to affect the crystalline surface only during weeks of experiments. ${ }^{7}$ This was obviously not true
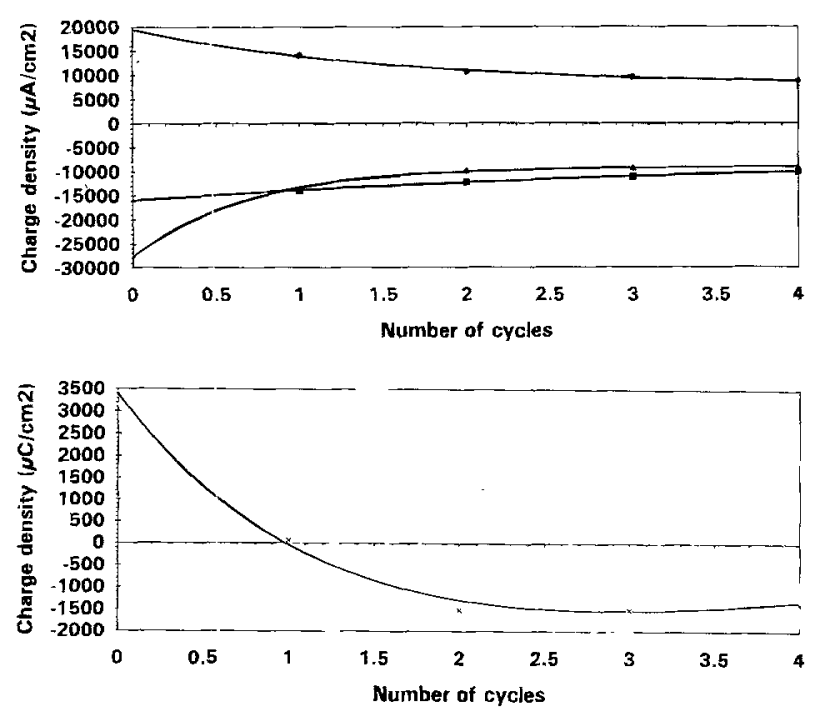

Fig. 9. Change in charge density during the first four cycles of bulk copper electrodeposition and subsequent dissolution (Fig. 6); (a, top) (D)-Charge of cathodic current transient of Fig. 6 when the potential was swept from $E=100 \mathrm{mV}$ to $E=-100 \mathrm{mV}$. (A) Charge of cathodic current transienf when the potential was swept from $E=-100 \mathrm{mV}$ and to the cathodic potential of zero current. (O) Charge of the anodic part of the current transient (Fig. 6$)$; (b, bottom) Difference in charge density between the anodic current fransients $(O)$ and the cathodic transients (a) ||$\left.Q_{3}|-| Q_{1} \mid\right)$ as a function of number of cycles. Exponential relationships were fitted to the data (full lines, see text and Table ( for details).
Table $I$. Values of charge densities $(Q)$ and exponential decay constants $\left(c_{Q}\right)$ obtained by fitting the function of Eq. 5 to the data of Fig. 9. (See text for the definition of areas in Fig. 6.)

\begin{tabular}{cccc}
\hline $\begin{array}{c}\text { Area } \\
\text { no. }\end{array}$ & $\begin{array}{c}Q_{\text {alloy }}\left(\mathrm{mC} / \mathrm{cm}^{2}\right) \\
( \pm 2 \%)\end{array}$ & $\begin{array}{c}Q_{\text {gold }}\left(\mathrm{mC} / \mathrm{cm}^{2}\right) \\
( \pm 2 \%)\end{array}$ & $\begin{array}{c}c_{Q}\left(\mathrm{cycles}^{-1}\right) \\
( \pm 10 \%)\end{array}$ \\
\hline 1 & $-6,800$ & $-16,000$ & -0.26 \\
2 & $-9,000$ & $-27,800$ & -1.46 \\
3 & $-7,900$ & $-19,400$ & -0.66
\end{tabular}

for the pc Au surface as evidenced by Fig. 2a-d. As the charge $(Q)$ and peak potential $\left(E_{\mathrm{P}}\right)$ experience large changes owing to a decrease in surface effective area and a subsequent growth of a surface phase, it is suggested that the recrystallization of the polycrystalline surface is indeed a faradaic process. Accordingly, in general theories of nucleation and electrocrystallization at low overpotentials ${ }^{35-37}$ a term of surface recrystallization in the case of a polycrystalline surface according to Eq. 6 should be included.

\section{Conclusions}

Imaging of electrochemical electrode processes in real time by in situ STM imaging combined with simultaneous electrochemical data acquisition have been applied to show the changes in surface morphology of a gold working electrode during initial cycles of potentiostatic bulk copper electrodeposition and subsequent dissolution.

1. After completion of the first cycle of bulk copper electrodeposition and dissolution the surface of the gold polycrystalline electrode exhibited a major transformation. It recrystallized and nuclei of a copper-gold alloy phase were formed on the top sites. The number density of alloy nuclei was $10^{10} \mathrm{~cm}^{-2}$.

2. Completion of subsequent cycles of bulk copper electrodeposition/dissolution resulted in minor transformations, such as a growth of nuclei into crystallites, an increase of crystallite dimensions, and a change of crystallites shape but left the basis of the recrystallized gold surface unaltered.
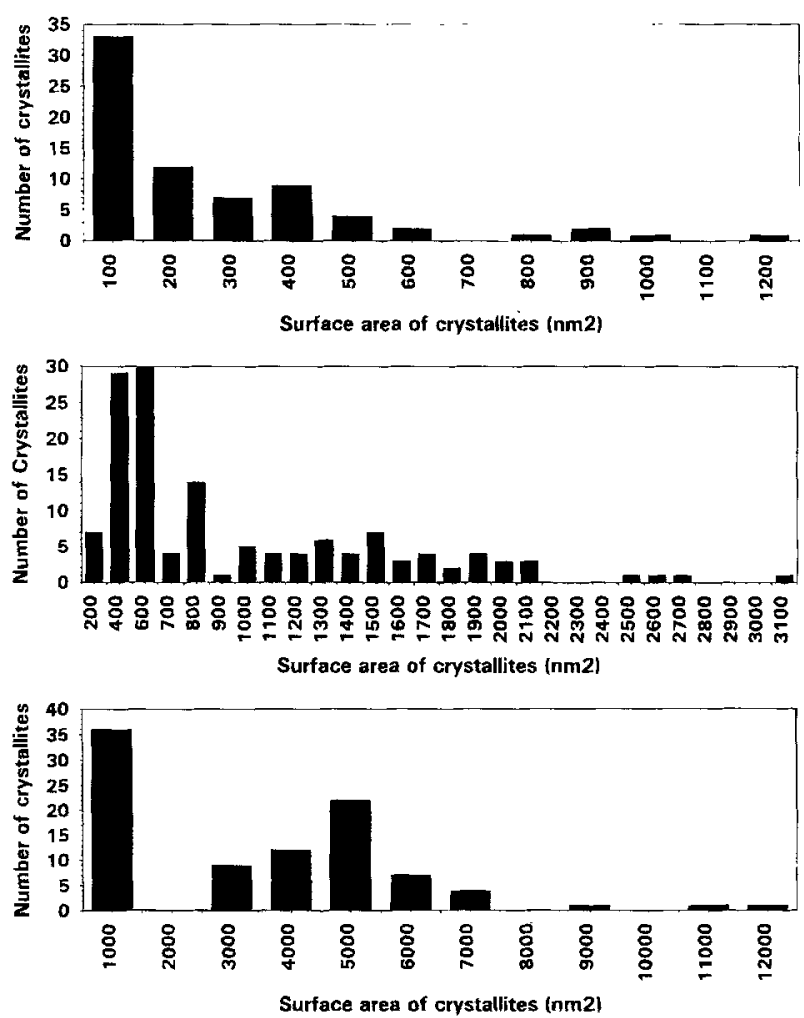

Fig. 10. Distribution of surface areas of nuclei and crystallites as deduced by in situ STM images: ( $a$, top) Fig. $2 b$; (b, middle) Fig. 2c; (c, bottom) Fig. 2d. 
3. The growth of dimensions of the crystallites increased both during the period of potentiostatic copper electrodeposition and during the period of potentiostatic dissolution. The alloy nuclei which were formed after completion of the first cycle were nucleation centers of copper growth in subsequent electrodepositions.

4. It is suggested that the growth of crystallites during the period of copper dissolution was due to a high surface mobility of gold atoms and that the gold layers trap copper atoms or copper ions, so as to form a copper deficient copper-gold alloy. The copper content of the alloy was estimated by voltammetry to be less than $10 \%$.

5 . The current transients of the first four cycles of potential sweep exhibit different behaviors. A shift of $22 \mathrm{mV}$ was observed for the anodic peak of current transient which was ascribed to a change in potential of the working electrode due to alloy formation. The initial shift in peak potential and the concomitant initial change of charge density of copper electrodeposition and dissolution were found to be related by a power law relationship.

\section{Acknowledgments}

This work was financially supported by the Danish Materials Research Programme and Danish Micro Engineering A/S. The technical assistance by Dr. C. E. Foverskov is gratefully acknowledged. Many thanks are due to Dr. Brücken (BASF, Germany) for providing the electropaint.

Manuscript submitted Aug. 15, 1994; revised manuscript received March 29, 1995.

The Technical University of Denmark assisted in meeting the publication costs of this article.

\section{REFERENCES}

1. J. Weichers, T. Twomey, D. M. Kolb, and R. J. Behm, J. Electroanal. Chem., 248, 451 (1988).

2. O. M. Magnussen, J. Hotlos, R. J. Nichols, and R. J. Behm, Phys. Rev. Lett., 64, 2929 (1990).

3. T. Hachiya, H. Honbo, and K. Itaya, J. Electroanal. Chem., 315, 275 (1991).

4. W. Haiss, D. Lackey, J. K. Sass, and K. H. Besocke, J. Chem. Phys., 95, 2193 (1991).

5. K. Sashikata, N. Furuya, and K. Itaya, J. Electroanal. Chem., 316, 361 (1991).

6. D. M. Kolb, in Structure of Electrified Interfaces, J. Lipkowski and P. N. Ross, Jr., Editors, Chap. 3, VCH Publishers, New York (1993).

7. R. J. Nichols, D. M. Kolb, and R. J. Behm, J. Electroanal. Chem., 313, 109 (1991).

8. D. M. Kolb, R. J. Nichols, and R. J. Behm, Electrified Interfaces in Physics, Chemistry and Biology, NATO ASI Series C, R. Guidelli, Editor, pp. 275-292, Kluwer Academic Publishers, Dordrecht, The
Netherlands (1992).

9. R. J. Nichols, W. Beckmann, H. Meyer, N. Batina, and D. M. Kolb, J. Electroanal. Chem., 330, 381 (1992).

10. X. G. Zhang and U. Stimming, ibid., 291, 273 (1990).

11. M. J. Armstrong and R. H. Muller, This Journal, 138, $2303(1991)$

12. R. J. Nichols, D. Schröer, and H. Meyer, Scanning, 15, 266 (1993).

13. J. E. T. Anderson, G. Bech-Nielsen, and P. Møller, Surf. Coat. Technol., 67, 151 (1994).

14. W. Haiss, D. Lackey, J. K. Sass, H. Meyer, and R. J. Nichols, Chem. Phys. Lett., 200, 343 (1992).

15. R. J. Nichols, O. M. Magnussen, J. Hotlos, T. Twomey, R. J. Behm, and D. M. Kolb, J. Electroanal. Chem., 290, 21 (1990).

16. X. Gao, A. Hamelin, and M. J. Weaver, Phys. Rev. Lett., 67, 618 (1991).

17. N. J. Tao and S. M. Lindsay, Surf. Sci, Lett., 274, L546 (1992).

18. C. Alonso, R. C. Salvarezza, J. M. Vara, A. J. Arvià, L. Vázquez, A. Bartolomé, and A. M. Barón, This Journal, 137, 2161 (1990).

19. C. Alonso, R. C. Salvarezza, J. M. Vara, and A. J. Arvia, Electrochim. Acta, 35, 1331 (1990).

20. J. M. Doña and J. González-Velasco, Surf. Sci., 274, 205 (1992).

21. J. D. Fritz and H. W. Pickering, This Journal, 138, 3209 (1991).

22. H. W. Pickering, Corros. Sci., 23, 1107 (1983).

23. T. P. Moffat, F.-R. F. Fan, and A. J. Bard, This Journal, 138, 3224 (1991)

24. C. E. Bach, R. J. Nichols, W. Beckmann, H. Meyer, A. Schulte, J. O. Besenhard, and P. D. Jannakoudakis, ibid., 140, 1281 (1993).

25. S. Manne, P. K. Hansma, J. Massie, V. B. Elings, and A. A. Gewirth, Science, 251, 183 (1991).

26. J. E. T. Andersen, G. Bech-Nielsen, and P. Møller, Surf. Coat. Technol., Submitted for publication.

27. J. Flach and J. E. T. Andersen, Unpublished results

28. D. M. Kolb and J. Schneider, Electrochim. Acta, 31, 929 (1986).

29. Z. Borkowska and U. Stimming, J. Electroanal. Chem., 312, 237 (1991)

30. Z. Shi and J. Lipkowski, ibid., 364, 289 (1994)

31. M. Wünsche, R. J. Nichols, R. Schumacher, W. Beckmann, and $\mathrm{H}$. Meyer, Electrochim. Acta, 38, 647 (1993).

32. M. P. Green, K. J. Hanson, R. Carr, and I. Lindau, This Journal, 137, 3493 (1990).

33. C. M. Vitus and A. J. Davenport, ibid., 141, 1291 (1994).

34. R. M. Rynders and R. C. Alkire, ibid., 141, 1166 (1994).

35. A. Milchev, J. Electroanal. Chem., 312, 267 (1991).

36. A. Milchev, W. S. Kruijt, M. Sluyters-Rehbach, and J. H. Sluyters, ibid., 362, 21 (1993).

37. A. I. Danilov and Yu. M. Polukarov, Russian Chem. Rev., 56, 619 (1987) 